\title{
Histochemical Investigation of the Modal Specificity of Taste
}

\author{
BRUCE TREFZ \\ School of Dentistry, University of Michigan, Ann Arbor, Michigan 48104, USA
}

The taste mechanism was investigated in a primate (Macaca mulatta). Based on the hypothesis that intracellular enzymes contribute to the transduction of tastes to electric impulses by taste cells, a histochemical survey of the activity of several enzymes was made on taste buds from regions of the mouth associated with sweet, salt, sour, and bitter tastes. Considerable differences were noted among the modalities, which confirmed the hypothesis. An exclusively bitter enzyme was identified.

The sense of taste is unique among the "chemical" senses, in that it is associated with discrete receptor organs of non-neural derivation, the taste buds. Their existence in humans has been recognized for more than a hundred years, ${ }^{1}$ but their exact mode of function remains obscure.

Classically, taste has been subdivided into four modalities, sweet, salt, bitter, and sour (acid). Each of these modalities has been localized to a discrete region on the surface of the tongue: sweet, to the fungiform papillae of the tip of the dorsum; salt, to the fungiform papillae of the lateral aspects of the anterior two thirds of the dorsum; bitter, to the circumvallate papillae of the posterior third of the dorsum; and sour, to the foliate papillae of the lateral aspects of the posetrior third of the dorsum (Fig 1)..$^{2}$

In 1951, Baradi and Bourne ${ }^{3}$ proposed a theoretical taste mechanism wherein the substance being tasted either inhibited or accelerated the rate of an on-going biochemical reaction in a taste region by alter-

This study was supported by funds from undergraduate research fellowships awarded in 1970 and 1971 by the School of Dentistry, University of Michigan and by USPHS Research Grant DE- 01604 from the National Institute of Dental Research, National Institutes of Health, Bethesda, Md.

Hatton award: 1st piace, predoctoral division. ing the efficacy of the enzyme that catalyzed the reaction. A net change in a reaction, then, was the source of the taste impulse, and the fact that enzymes are highly specific accounted for the specificity of the taste impulse. If this hypothesis is valid, the taste buds from a region of predominantly one modality should display an enzyme complement different from that of a region of another modality.

More recent research ${ }^{4}$ has shown that taste cells have differing enzyme complements at different stages in their fetal development; perhaps this reflects the developing, and therefore changing, level of function.

It is not unlikely that taste buds of differing modalities also have differing enzymatic compositions, although currently this is a topic of conjecture.

The enzyme complements of the taste buds of the four classical modalities were assayed histochemically, and their specificities, localizations, and intensities were determined.

\section{Materials and Methods}

Adult rhesus monkeys (Macaca mulatta) were used. All monkeys were killed by vascular perfusion of physiologic isosmotic saline while they were under anesthesia. Tongues were removed by incision posterior to the circumvallate papillae. Immediately after excision, regions containing taste buds were removed from well within the boundaries of the areas classically assigned to each of the modalities (Fig 2). The tissue then was frozen in liquid nitrogen-isopentane, sectioned at 12 micrometers on a cryostat, $^{*}$ and mounted on microslides. With each modality, the tissue blocks were oriented so that the microtome cut the taste

\footnotetext{
* American Optical "Cryo-Cut," American Optical Co., Instrument Division, Buffalo, NY.
} 


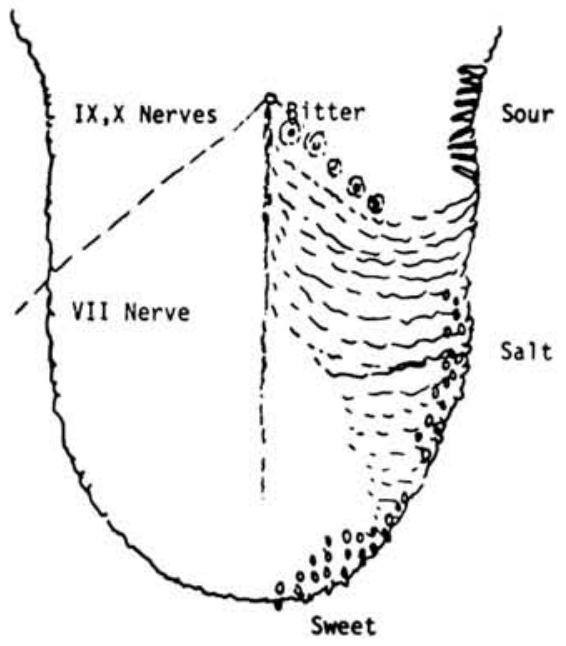

FIG 1.-Classical taste modality localization on the tongue.
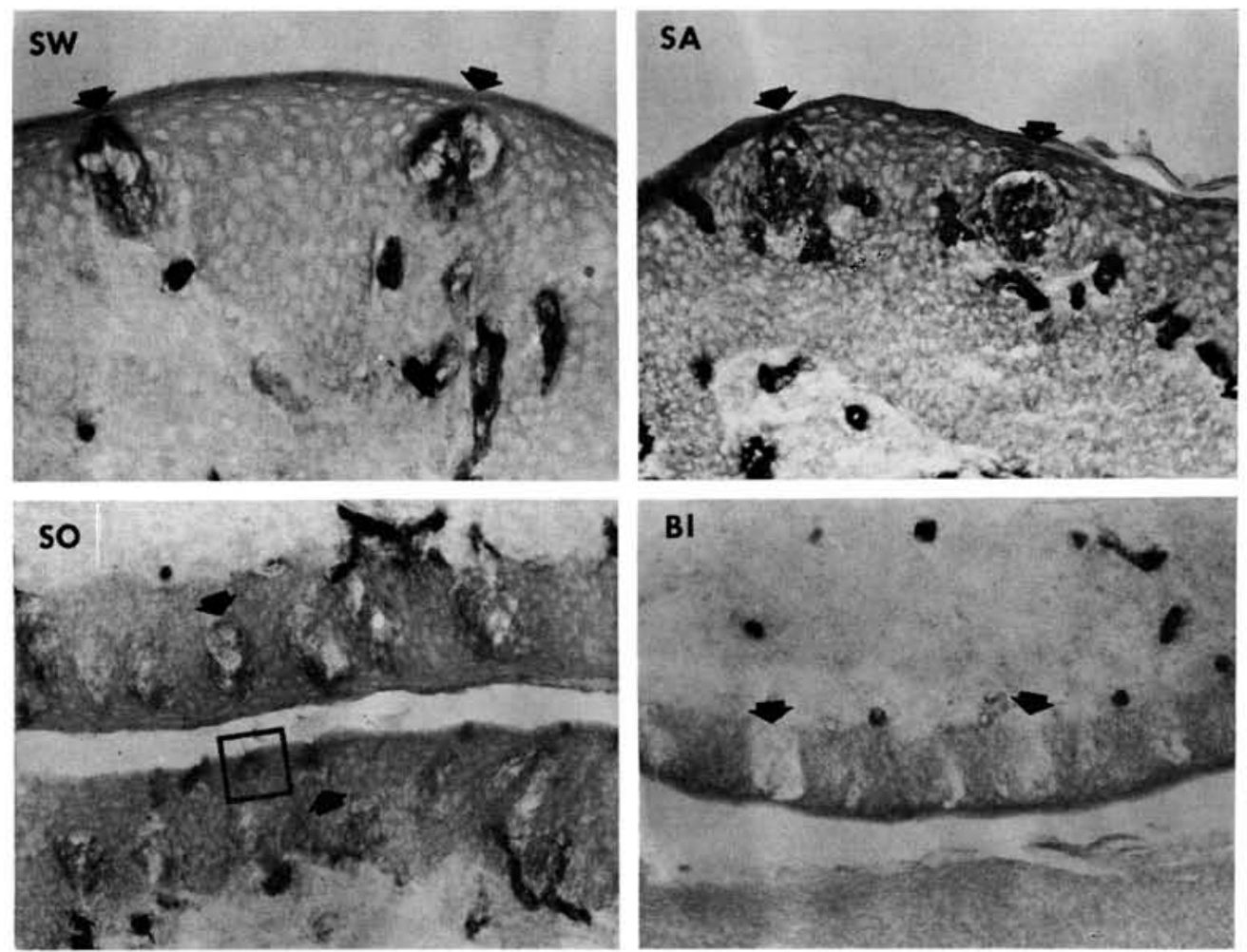

FIG 3.-Alkaline phosphatase. Sweet $(S W)$ and salt $(S A)$ displayed activity throughout taste buds (arrows), but sour $(S O)$ and bitter $(B I)$ stained only lightly and principally in the region of the taste pore (square) where the oral fluids contact the taste cells (orig mag $\times 200$, reproduced at $56 \%$ ). 
TABLE

Enzymatic Activity in Taste Buds

\begin{tabular}{|c|c|c|c|c|}
\hline Enzyme & Sweet & Salt & Sour & Bitter \\
\hline Succinic dehydrogenase & - & - & & +- \\
\hline Choline oxidase & $++t$ & + & & \\
\hline Cytochrome oxidase & & + & & \\
\hline Nonspecific esterase & & - & & \\
\hline NAD diaphorase & & & & \\
\hline $\begin{array}{l}\text { NADP diaphorase } \\
\alpha \text {-Glycerophosphate }\end{array}$ & & + & & \\
\hline dehydrogenase & + & + & ++ & ++ \\
\hline$\beta$-Hydroxybutyric & & & & \\
\hline dehydrogenase & - & - & & \\
\hline D-amino acid oxidase & + & + & & \\
\hline Alkaline phosphatase & ++ & $t+t$ & & \\
\hline $\begin{array}{l}\text { Glucose-6-phosphate } \\
\text { dehydrogenase }\end{array}$ & & - & & \\
\hline Acid phosphatase & & + & & \\
\hline Adenosine triphosphatase & & + & & \\
\hline Nucleotide diphosphatase & & $+t$ & 7 & \\
\hline
\end{tabular}

buds in the long axis to facilitate comparison.

The following are the enzyme systems examined and the pathways they represent: succinic dehydrogenase ${ }^{5}$ (Krebs cycle ac- tivity); choline oxidase, ${ }^{6}$ cytochrome oxidase, ${ }^{7} \quad \alpha$-glycerophosphate dehydrogenase, ${ }^{8}$ $\beta$-hydroxybutyric dehydrogenase, ${ }^{9}$ and $\mathrm{D}$ amino acid oxidase $^{6}$ (electron transport chain activity); nonspecific esterase ${ }^{10}$ (mem-
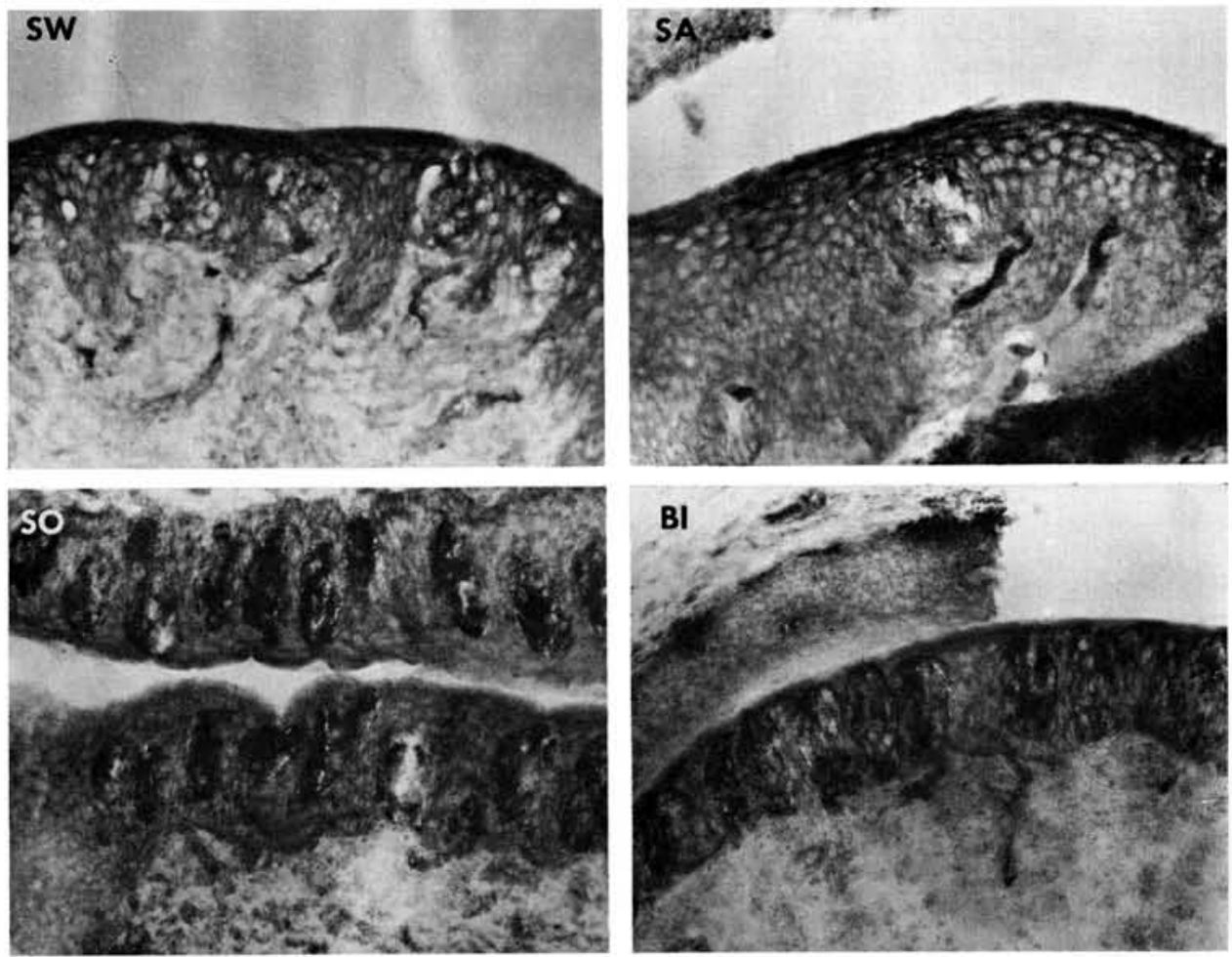

FIg 4.-Acid phosphatase. Sour ( $S O)$ and bitter $(B I)$ taste buds stained darkly (great activity) and sweet $(S W)$ and salt $(S A)$ buds showed only minimal activity, also in the region of the pore (orig mag $\times 200$, reproduced at $58 \%$ ). 

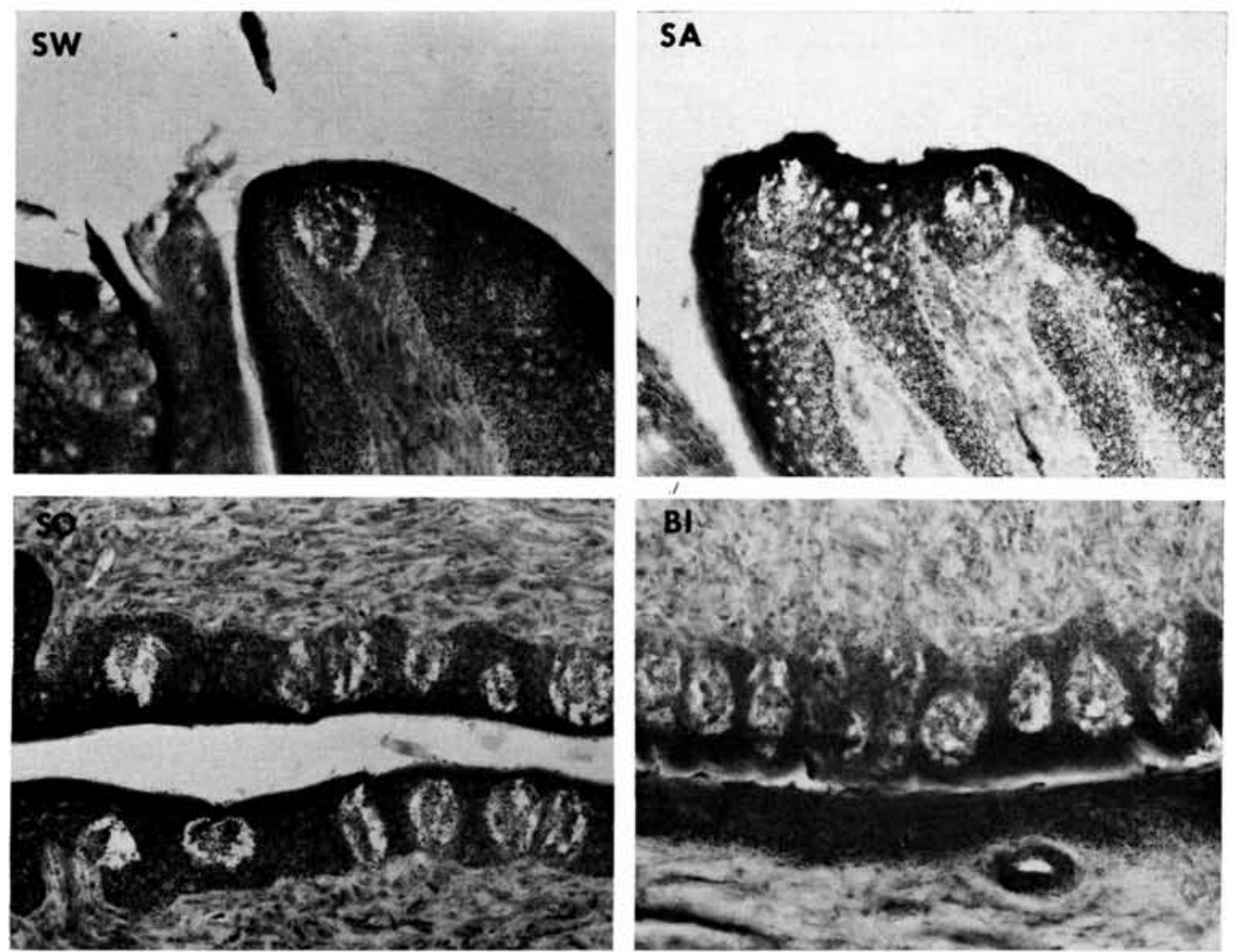

FIg 5.-Succinic dehydrogenase. Sour $(S O)$ and bitter $(B I)$ taste buds displayed more activity than sweet $(S W)$ or salt $(S A)$ buds, but there was no activity in the pore regions of sweet and salt buds (orig mag $\times 200$, reproduced at $57 \%$ ).

brane-bound hydrolytic activity); NAD diaphorase ${ }^{11}$ and NADP diaphorase ${ }^{7}$ (membrane-bound pentose-phosphate shunt activity); glucose-6-phosphate dehydrogenase ${ }^{12}$ (soluble pentose-phosphate shunt activity); adenosine triphosphatase ${ }^{13}$ (mitochondrial activity); and nucleotide diphosphatase ${ }^{14}$ (Golgi complex activity). Finally, because several investigators have attributed great importance to the role of hydrolytic enzymes in the process of taste, ${ }^{5.15}$ alkaline phosphatase ${ }^{16}$ (active transport activity) and acid phosphatase ${ }^{17}$ (lysosomal activity) were examined. In all instances, the exact methods of the investigators cited were used. As a further control, all four modalities in each assay came from the same monkey, and were incubated simultaneously in the same medium for the same amount of time. In addition, at least two, and as many as six repetitions were performed for each assay until consistent results were obtained. All the data presented here repre- sent the mean, consistent values obtained for each enzyme. The photomicroscope ${ }^{*}$ used was set for constant light intensity and exposure values.

\section{Results}

Each of the enzymes studied was present in the taste bud cells, but response in the surrounding epithelium, from which the taste cells are derived, was variable. A synopsis of the observed enzymatic activity in the taste buds is presented in the table. Enzyme activities are indicated by the observed depth of the staining reaction in the range of - (absent) to ++++ (highly active).

The values in the table were obtained by microdensitometric measurement of stain intensity within the taste buds and by comparison of the mean obtained for each modality with the other modality means for each enzyme.

\footnotetext{
* Carl Zeiss, Inc., New York, NY.
} 

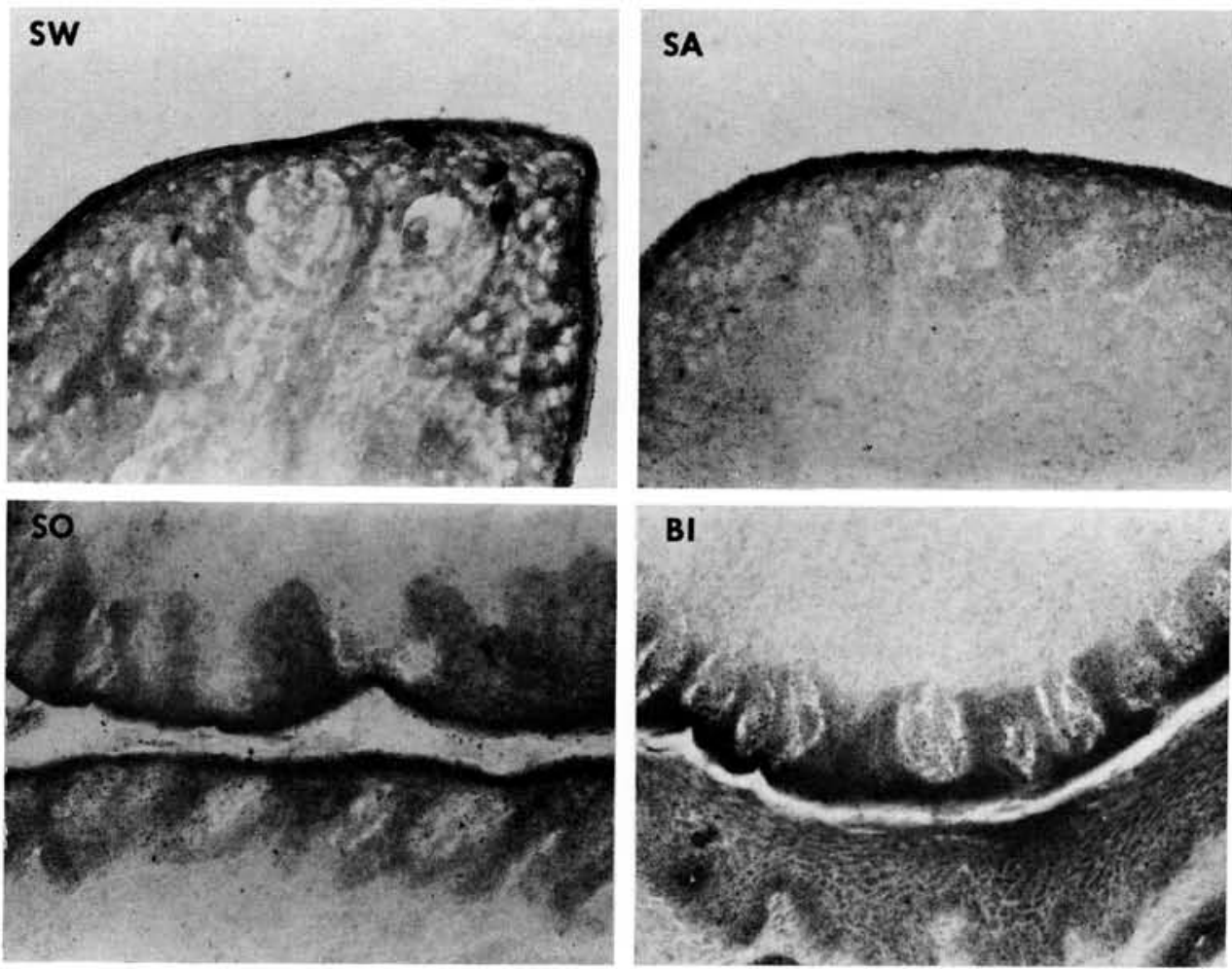

FIg 6.-Beta-hydroxybutyric dehydrogenase. Sweet $(S W)$, salt $(S A)$, and sour $(S O)$ taste buds displayed little activity, but the bitter taste buds $(B I)$ showed considerable activity, especially in the surrounding epithelium (orig mag $\times 200$, reproduced at $56 \%$ ).

Alkaline phosphatase (Fig 3) reacted strongly in the sweet and salt modalities, and reacted hardly at all in the bitter and sour modalities. All activity seemed to be concentrated in the region of the taste pore in the sour and bitter buds, whereas the sweet and salt buds stained rather generally and very darkly. This situation is reversed in the acid phosphatase reaction (Fig 4); sour and bitter stained heavily throughout, and sweet and salt showed only slight activity, which is concentrated in the region of the pore. The characteristic staining of the capillary endothelium by the alkaline phosphatase reaction is evident and unifrom through the different modalities.

The activity of succinic dehydrogenase (Fig 5) seemed to parallel that of acid phosphatase, with the exception of the pore regions of the sweet and salt buds, which displayed no special activity.

Beta-hydroxybutyric dehydrogenase (Fig
6) appeared to be specific for the bitter modality; all the other modalities displayed no activity. The reaction in the surrounding epithelium was especially notable.

NADP diaphorase (Fig 7) displayed a spectrum of activity that can be graded as least in sweet, progressively more in salt and sour, and most in bitter.

Alpha-glycerophosphate dehydrogenase (Fig 8) showed its strongest activity in the sour and bitter modalities, with heavy epithelial activity around the taste buds. This is especially apparent in the bitter (circumvallate papilla) region, where the heavily stained gustatory epithelium opposed a nonneural epithelium that showed essentially no activity.

Other enzymes studied, but not photographed, showed measurable but somewhat less striking results (Table): Cytochrome oxidase, D-amino acid oxidase, and glucose6-phosphate dehydrogenase displayed fairly 

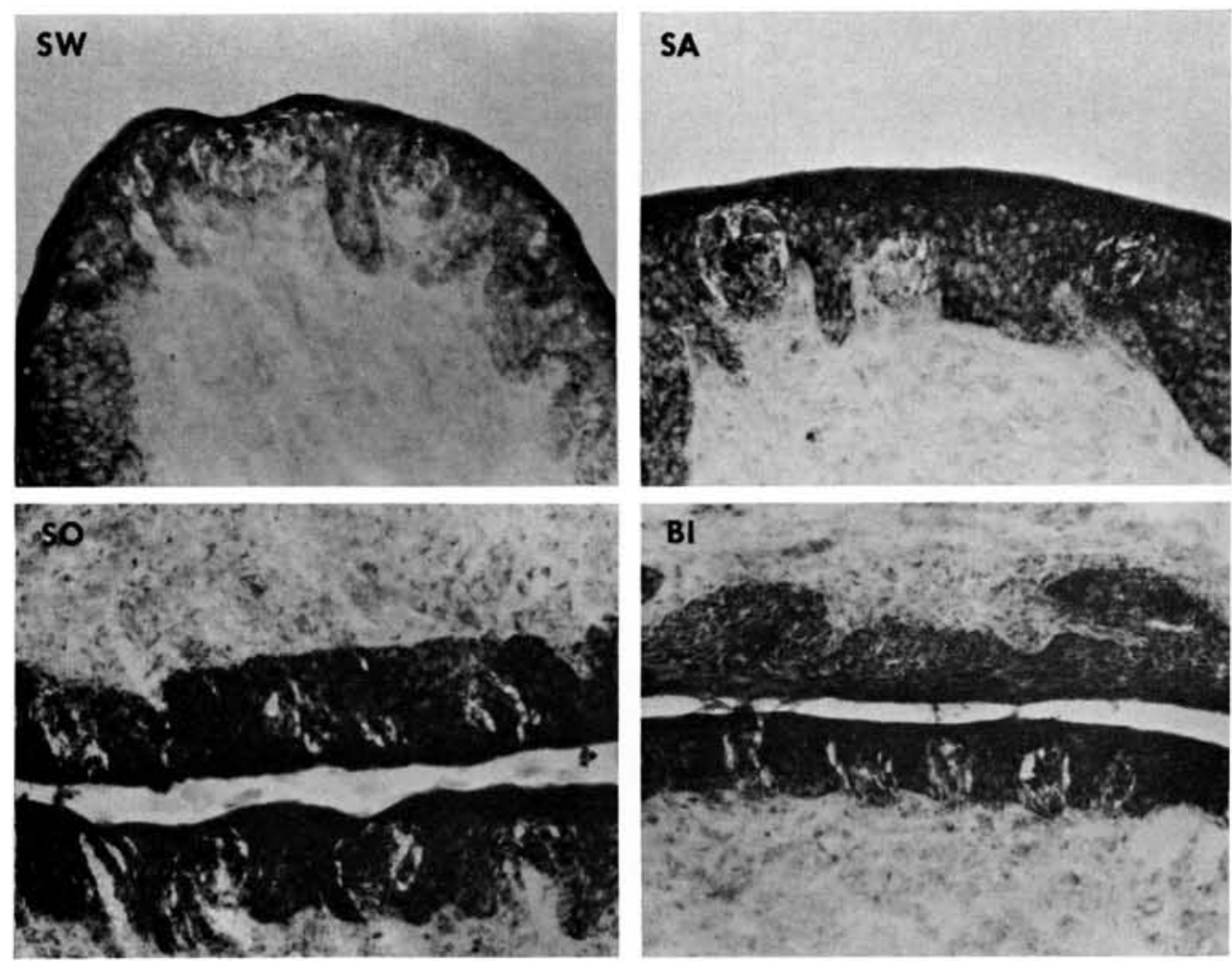

Fig 7.-NAPD diaphorase. Taste bud enzyme activity was graded from least to most in the following order: sweet $(S W)$, salt $(S A)$, sour $(S O)$, and bitter $(B I)$ (orig mag $\times 200$, reproduced at $56 \%$ ).

even staining from modality to modality. The same is true for adenosine triphosphate and nucleotide diphosphatase, but sharp intracellular differences were apparent. Adenosine triphosphatase stained the cell membranes of all four modalities sharply, but the pore regions in the sour modality, and especially the bitter modality, displayed intense activity. Nucleotide diphosphatase, however, darkly stained the nuclei of only some of the cells of the buds of all four modalities and the pore regions in all modalities except salt. NAD diaphorase had a graded spectrum of activity that was similar, but not identical to that of NADP diaphorase. Choline oxidase and nonspecific esterase showed activity in all the modalities except salt; greater differences were noted with choline oxidase.

\section{Discussion}

Succinic dehydrogenase has long been used as a marker for the activity of the
Krebs cycle, ${ }^{5}$ especially in the taste buds. ${ }^{18}$ Its localization in significant amounts in sour and bitter taste buds, but not in sweet or salt buds, infers that in the former two modalities the missing electrochemical impulse conversion system of Baradi and Bourne, ${ }^{3,19}$ is in some way linked to the Krebs tricarboxylic acid cycle.

High acid phosphatase activity in sour and bitter taste buds and low activity in sweet and salt buds is to be expected, because most sour and bitter substances are acidic to some degree, ${ }^{20}$ and lysosomes, which contain the enzyme, have been observed in ultrastructural studies of foliate and circumvallate papillae in lower species. ${ }^{21,22}$ In addition, it is a lytic phosphatecleaving enzyme that lends itself to energy mediation. ${ }^{23}$ This fact also is true of alkaline phosphatase, which is sweet- and saltspecific; but, in addition, alkaline phosphatase is an energy-mediating enzyme often associated with active transport at the cell- 

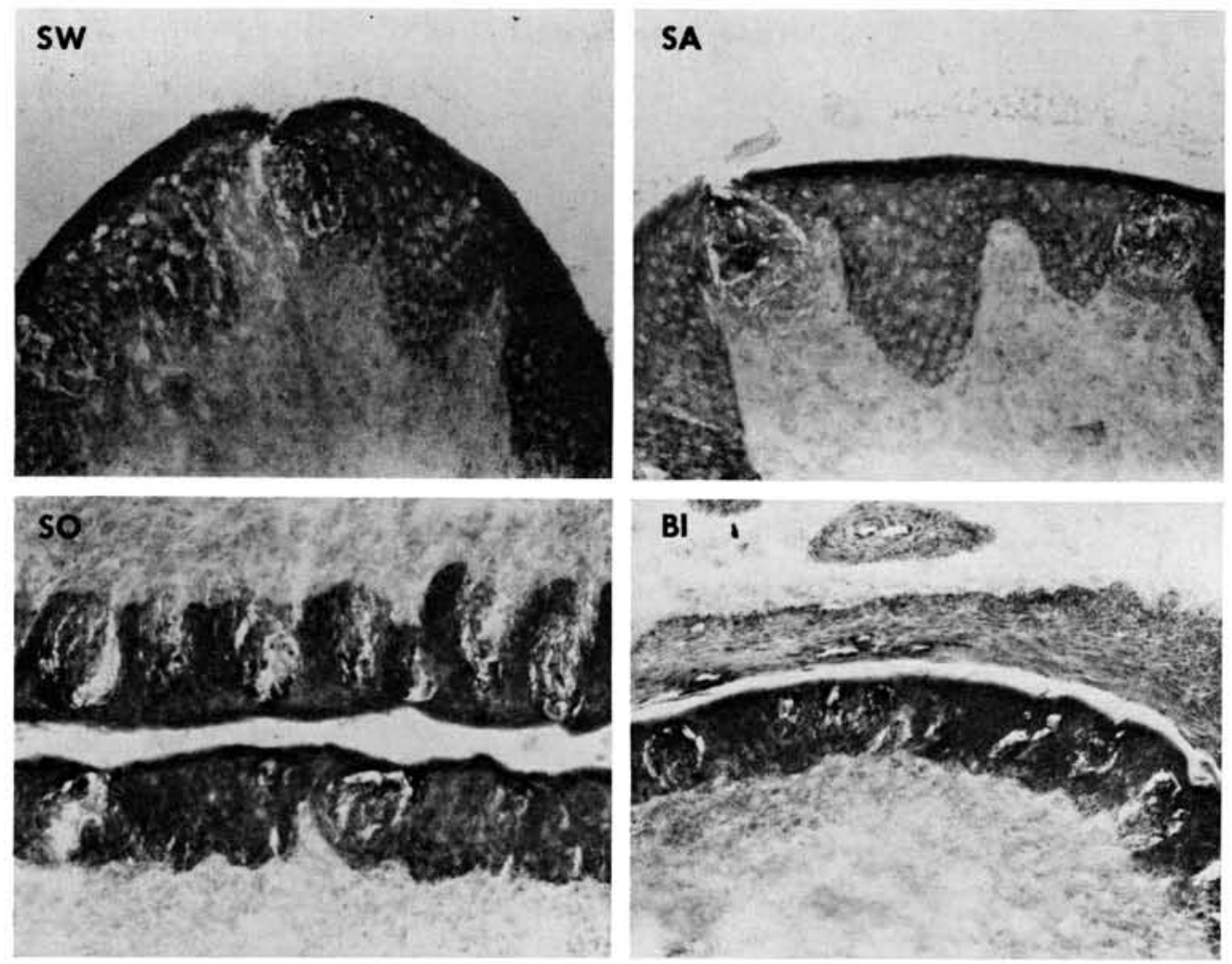

FIG 8.-Alpha-glycerophosphate dehydrogenase. More activity was evident in sour (SO) and bitter $(B I)$ taste buds than in sweet $(S W)$ or salt $(S A)$ buds. Notable activity in epithelium surrounding sour and bitter taste buds was present (orig mag $\times 200$, reproduced at $56 \%$ ).

membrane level, ${ }^{24}$ as evidenced by its previously noted activity in capillary endotheliums. Alkaline phosphatase may be the electrochemical converter for sweet and salty tastes.

Choline oxidase, $\alpha$-glycerophosphate dehydrogenase, $\beta$-hydroxybutyric dehydrogenase, and D-amino acid oxidase are indicators of the so called electron-transport chain, ${ }^{25}$ another cellular energy path. The varying results observed in the four modalities for these four enzymes points convincingly toward enzymatic specificity as the determining factor in taste specificity. In addition, $\beta$-hydroxybutyric dehydrogenase may well be a true "bitter enzyme."

The other enzymes assayed all showed varying differences both among themselves and among the four modalities. All were linked to either a metabolic pathway (NAD and NADP diaphorase, membrane-bound pentose phosphate shunt ${ }^{26}$ and glucose-6- phosphate dehydrogenase, free cytoplasmic pentose phosphate shunt ${ }^{27}$ ), or to a biologic function associated with a discrete ultrastructural entity (adenosine triphosphatase, mitochondria ${ }^{11}$; nucleotide diphosphatase, Golgi apparatus, ${ }^{28}$ and nonspecific esterase, ribosomes and rough-surfaced endoplasmic reticulum ${ }^{29}$ ).

This wide variation of enzymatic activity, and wide variation of kinds and types of enzymes involved, easily explains why we are capable of more than 16 tastes (the maximum number of combinations and permutations of the four basic taste modalities). This study only considered a fraction of the enzymes that occur in cells, but variations were found from modality to modality in almost every enzyme studied. One notable exception is cytochrome oxidase, which is an indicator of anaerobic metabolic activity. ${ }^{30}$ As expected, the activity is relatively constant from cell to cell; this may imply 
that the ultimate transmission (or transduction or both) of the taste signal is by an aerobic pathway, rather than by an anaerobic, pathway.

An overall survey of the data in the table indicates the following generalized subgrouping, on the basis of enzyme activities; sweet with salt and sour with bitter. This may be of developmental significance, since sweet and salt taste buds receive their innervation from the VII nerve, and sour and bitter taste buds from the IX and X nerves (Fig 1), which supply structures derived from different branchial arches.

This fact is of medical interest, because diminutions in taste acuity of these modal subgroups that occur in certain human diseases have been noted and are well-documented. ${ }^{31}$ Sweet functions with salt, and sour with bitter, and the two subunits operate quite independently of each other during the course of therapy.

\section{Conclusions}

The mechanism of taste was studied histochemically in a primate. Notable differences in enzymatic activity were demonstrated among taste buds from tongue regions associated with sweet, salt, sour, and bitter taste. The hypothesis of Baradi and Bourne $^{32}$ that the specificity and transduction of the taste impulse is due to specific enzymatic involvement was confirmed. Functional association was noted between sweet and salt enzymatic activity, and between sour and bitter enzymatic activity; this agrees with clinical findings. A bitterspecific enzyme, $\beta$-hydroxybutyric dehydrogenase, was identified.

The author thanks his sponsor, J. K. Avery, of the Laboratory of Oral Histology, School of Dentistry, University of Michigan for encouragement and advice and $C$. Cox, of the same institution, for his aid in the technical aspects of this study.

\section{References}

1. Loven, O.C.: Bidrag till Kannendomen om tungans smakpapiller, Med Arch (Stockholm) 3(9):1, 1867.

2. AdEY, W.R.: The Sense of Smell, in Field, J.; Magoun, H.W.; and Hall, V.E. (eds), Handbook of Physiology, vol I, Washington: American Physiological Society, 1959, p 481.

3. Baradi, A.F., and Bourne, G.H.: Localization of Gustatory and Olfactory En- zymes in the Rabbit, and the Problem of Taste and Smell, Nature (Lond) 168: 977, 1951.

4. Nada, O., and Iwayama, T.: Histochemical Observation on the Phosphatase Activities of the Differentiating Taste Bud, Anat Rec 165(1):61, 1969.

5. Defendi, V., and Pearson, B.: Quantitative Estimation of Succinic Dehydrogenase Activity in a Single Microscopic Tissue Section, $J$ Histochem Cytochem 3:61, 1955.

6. Farber, E.; Sternierg, W.H.; and Pearce, N.A.M.: Histochemical Localization of Choline Oxidase and D-Amino Acid Oxidase with Tetrazolium Salts and Phenozine Methosulfate, J Histochem Cytochem 6: $389,1958$.

7. Altmann, F.P.: The Cellular Chemistry of Certain Cytoplasmic Oxidative Enzymes and Their Relevance to the Metabolism of Cancers, $\mathrm{PhD}$ thesis, University of London, 1968.

8. Biochemists' Handbook, Long, C. (ed), London: Spon, 1961, p 368.

9. Hess, R.: Beta-Hydroxybutyric Dehydrogenase Activity in Tumors, Am J Pathol 37:583, 1960.

10. Burstone, M.S.: The Relationship Between Fixation and Techniques for the Histochemical Localization of Hydrolytic enzymes, $J$ Histochem Cytochem 6:322, 1958.

11. Dixon, M., and Werb, E.C.: Enzymes, 2nd ed, London: Longmans, 1964, p 233.

12. ChIQuolne, A.D.: The Distribution of Glucose-6-Phosphatase in the Liver and Kidney of the Mouse, $J$ Histochem Cytochem 1: $429,1953$.

13. Wachstein, M., and Meisel, E.: Histochemistry of Substrate-Specific Phosphatases at a Physiological pH, $J$ Histochem Cytochem 4:424, 1956.

14. NovikofF, A., and GoldFischer, S.: Nucleotide Diphosphatase Activity in the Golgi Apparatus, Proc Natl Acad Sci 47: $802,1961$.

15. Bourne, G.H.: Alkaline Phosphatase in Taste Buds and Nasal Mucosa, Nature (Lond) 161:444, 1948.

16. Burstone, M.S.: Histochemical Demonstration of Acid Phosphatases with Naphthol AS-Phosphates, $J$ Natl Cancer Inst 19: $523,1958$.

17. Gomori, G.: Microscopic Histochemistry, Principles and Practice, Chicago: University of Chicago Press, 1952, p 193.

18. Pevzner, R.A.: Determination of the Succinic Dehydrogenase Activity in Taste Buds of Some Vertebrate Mammals, Dokl Akad Nauk SSSR 155:191, 1964.

19. BARADI, A.F., and Bourne, G.H.: New Observations on the Alkaline Phosphatase 
Reaction in the Papilla Foliata, J Biophys Biochem Cytol 5:173, 1959.

20. Von Bekesy, G.: The Duplexity Theory of Taste, Science 145:834, 1964.

21. Farbman, A.I.: Fine Structure of the Taste Bud, $J$ Ultrastruct Res 12:328, 1965.

22. NemetsChex-Gansler, H., and Ferner, H.: On the Ultrastructure of the Taste Buds, $Z$ Zellforsch Mikrosk Anat 63:155, 1964.

23. DeDuve, C.: Lysosomes, a New Group of Cytoplasmic Particles, Hayashi, T. (ed): Subcellular Particles, New York: Ronald, 1959.

24. Danielli, J.F.: Cytochemistry: A Critical Approach, London: Chapman and Hall, 1953, p 81.

25. Farber, E.: Principles of Oxidative Enzyme Histochemistry, in Histochemistry, Kansas City: University of Kansas Press, 1964, p 11.

26. BuRstone, M.S.: Histochemical Demonstration of Cytochrome Oxidase with New
Amine Reagents, $J$ Histochem Cytochem 8:63, 1960 .

27. Altmann, F.P.: The Retention and Estimation of "Soluble" Dehydrogenases in Unfixed Tissue Sections, Biochem J 96:53, 1965.

28. Novikoff, A.; Goldfischer, S.; and EssNER, E.: The Importance of Fixation in a Cytochemical Method for the Golgi Apparatus, J Histochem Cytochem 9:459, 1961.

29. Underhay, E.; Holt, S.J.; Beaufay, H.; and DeDuge, C.: Intracellular Localization of Esterase in Rat Liver, $J$ Biophys Biochem Cytol 2:635, 1956.

30. West, E.S., and ToDD, W.R.: Textbook of Biochemistry, New York: Macmillan, 1961, p 853.

31. Henkin, R.I.; Graziadei, P.P.; and BradLEY, B.F.: NIH Clinical Staff Conference: The Molecular Basis of Taste and Its Disorders, Ann Intern Med 71:791, 1969.

32. Baradi, A.F., and Bourne, G.H.: Theory of Taste and Odors, Science 113:660, 1951. 